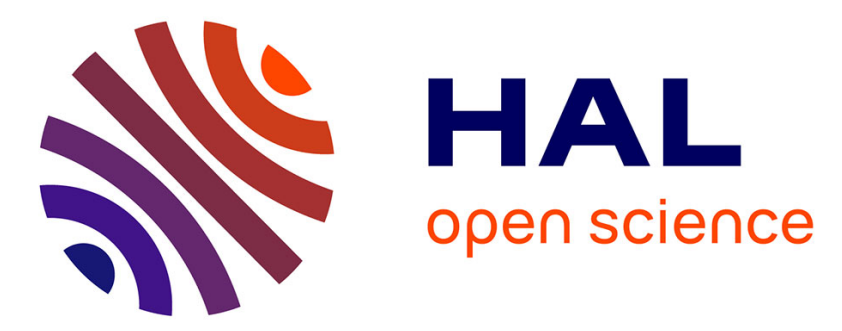

\title{
Effect of Temperature and Mechanical Stress on Barrier Properties of Polymeric Films Used for Food Packaging
}

Saša Mrkić, Kata Galić, Marica Ivanković

\section{To cite this version:}

Saša Mrkić, Kata Galić, Marica Ivanković. Effect of Temperature and Mechanical Stress on Barrier Properties of Polymeric Films Used for Food Packaging. Journal of Plastic Film and Sheeting, 2007, 23 (3), pp.239-256. 10.1177/8756087907086102 . hal-00572074

\section{HAL Id: hal-00572074 \\ https://hal.science/hal-00572074}

Submitted on 1 Mar 2011

HAL is a multi-disciplinary open access archive for the deposit and dissemination of scientific research documents, whether they are published or not. The documents may come from teaching and research institutions in France or abroad, or from public or private research centers.
L'archive ouverte pluridisciplinaire HAL, est destinée au dépôt et à la diffusion de documents scientifiques de niveau recherche, publiés ou non, émanant des établissements d'enseignement et de recherche français ou étrangers, des laboratoires publics ou privés. 


\title{
Effect of Temperature and Mechanical Stress on Barrier Properties of POLYMERIC FILMS USED FOR Food Packaging
}

\author{
Saša Mrkić, ${ }^{1}$ Kata Galić ${ }^{2, *}$ and Marica Ivanković ${ }^{3}$ \\ ${ }^{1}$ Kraš d.d., Ravnice 48, HR-10000 Zagreb Croatia \\ ${ }^{2}$ University of Zagreb, Faculty of Food Technology and Biotechnology \\ Pierottijeva 6, HR-10000 Zagreb, Croatia \\ ${ }^{3}$ University of Zagreb, Faculty of Chemical Engineering and Technology \\ Maruliceev trg 19, 10000 Zagreb, Croatia
}

\begin{abstract}
The permeance of carbon dioxide, oxygen, nitrogen, and air through commercial polymers based on polyethylene (PE), biaxially oriented polypropylene (BOPP), and polyamide (PA) used for food packaging is reported. The influence of temperature (from 10 to $60^{\circ} \mathrm{C}$ ) and crease stress cycles $(30,50$, 70 , and 110) on gas permeance is also analyzed. Generally, the highest changes in gas permeance changes with increased stress cycles are observed with films having a metallized layer in the structure, namely BOPPcoex/BOPPcoex.met and, to a lesser extent, BOPPcoex.met/PE laminate. The lowest crease stress influence on barrier properties is obtained for PE film. In this case, the highest activation energy for the permeability coefficient $(P)$ is obtained. Normal progressions of activation energies for $P$ are: $\mathrm{N}_{2}=$ Air $>\mathrm{CO}_{2}>\mathrm{O}_{2}$.
\end{abstract}

KEY WORDS: Crease strains, gas permeance, laminates, films, flex tests.

\section{INTRODUCTION}

THE USE OF different polymers, such as polyethylene (PE), polypropylene (PP), and polyamide (PA) in the foodstuffs packaging industry depends on the properties of the final product.

\footnotetext{
*Author to whom correspondence should be addressed. E-mail: kgalic@pbf.hr

Journal of PLASTIC FILM \& SHEETING, Vol. 23—July 2007 
Manufacturing, handling, and packaging procedures can greatly affect the barrier properties of flexible packaging materials.

The gas transport coefficients (permeability, the diffusion and the solubility coefficients) vary generally with parameters which can be intrinsic to the polymer, such as the degree of crystallinity, the nature of the polymer, or even the thermal and mechanical histories of samples [1]. The kind of gases used, characterized by its molecule size and nature as well as its conditions of temperature and pressure, are also factors influencing barrier properties. Molecular orientation which usually develops in processing is known to have a major effect on the mechanical properties of both glassy and crystalline polymers. The resistance to repeated flexure or creasing is important in use. Some films are highly resistant [2] whereas others will fail by pinholing or total fracture after bending only a few times. Even if failure does not occur, certain properties of the film may be seriously impaired. For example, permeability to gases or water vapor, tensile or optical properties may be seriously affected $[3,4]$. Additives to a plastic material to modify its properties generally increase the permeability. This increase is further affected with increased crease stress on polymers $[4,5]$.

Orientation of polymer materials reduces gas diffusivity. In a study of permeability of carbon dioxide $\left(\mathrm{CO}_{2}\right)$ through ultradrawn polystyrene, Wang and Porter [6] pointed out that the solubility remains nearly constant while the diffusion coefficient decreases with draw.

Today's polyolefin packaging can have a range of functional requirements, among them high flexibility, optical clarity, low water loss, sealability, extended shelf life, slow permeability to oxygen $\left(\mathrm{O}_{2}\right)$ and $\mathrm{CO}_{2}$, lack of leachables, dimensional stability during sterilization, flex resistance, biocompatibility and environmental compatibility, and low cost. PE was the first commodity plastic used for food packaging. PE films are often laminated with other polymers for applications in which PE is used for heat sealing and/or as a barrier to water vapor. Biaxially oriented polypropylene film (BOPP) is also a widely used transparent packaging material. Its advantageous properties include low density, no toxicity, good moisture resistance, good mechanical strength, and dimensional stability and printability. Commercial BOPP films have special inner structures obtained by the stretching of the thick, extruded sheets at high temperatures in the machine direction and in the transverse direction [7]. Polyamide has frequent use as a component in these multilayer film structures [8] due to its unique combination of mechanical strength, puncture resistance, transparency, thermal stability, $\mathrm{O}_{2}$ and aroma barrier, and thermoformability. A number of papers report on the effect of drawing on polymers permeability [6,9-11]. 
The present study focuses on the crease action influence on gas $\left(\mathrm{CO}_{2}, \mathrm{O}_{2}\right.$, nitrogen $\left(\mathrm{N}_{2}\right)$, and air) permeance changes through commercial mono- and di-layer films (PE, PA, BOPP, and metallized BOPP), used for food packaging.

\section{EXPERIMENTAL DETAILS}

The investigated test films are listed and specified in Table 1. Films were obtained, without graphics, directly from the producer, Aluflexpack d.o.o., Umag, Croatia.

\section{Permeance Measurement}

Gas permeance determination $[12,13]$ was performed by a manometric method using a permeance testing appliance, Brugger type GDP-E [14].

Table 1. Materials used in the experiments.

\begin{tabular}{|c|c|c|c|c|}
\hline & Polymer & Abbreviation & $\begin{array}{l}\text { Thickness } \\
\qquad(\mu \mathrm{m})\end{array}$ & Comments \\
\hline 1 & Polyethylene & PE & 75 & $\begin{array}{l}\text { Polyethylene low } \\
\text { density, PE-LD }\end{array}$ \\
\hline 2 & Polyamide & PA & 15 & $\begin{array}{l}\text { Polyamide 6; Density } \\
\left(23^{\circ} \mathrm{C}\right)=1.15 \mathrm{~g} \mathrm{~cm}^{-3}\end{array}$ \\
\hline 3 & $\begin{array}{l}\text { Bioriented coextruded } \\
\text { polypropylene }\end{array}$ & BOPP coex & 20 & \\
\hline 4 & $\begin{array}{l}\text { Bioriented coextruded } \\
\text { metallized polypropylene }\end{array}$ & BOPP coex.met & 20 & $\begin{array}{l}\text { Vacuum deposited } \\
\text { aluminum }\end{array}$ \\
\hline 5 & Polyamide/Polyethylene & PA/PE & $15 / 75$ & $\begin{array}{l}2.2-2.7 \mathrm{~g} \mathrm{~m}^{-2} \\
\text { polyurethane solvent } \\
\text { based adhesive }\end{array}$ \\
\hline 6 & $\begin{array}{l}\text { Polypropylene bioriented } \\
\text { coextruded/Polyethylene }\end{array}$ & BOPPcoex./PE & $20 / 75$ & $\begin{array}{l}2.5-3.0 \mathrm{~g} \mathrm{~m}^{-2} \\
\text { polyurethane solvent } \\
\text { based adhesive }\end{array}$ \\
\hline 7 & $\begin{array}{l}\text { Polypropylene bioriented } \\
\text { coextruded metallized/ } \\
\text { Polyethylene }\end{array}$ & BOPPcoex.met./PE & $20 / 75$ & $\begin{array}{l}2.5-3.0 \mathrm{~g} \mathrm{~m}^{-2} \\
\text { polyurethane solvent } \\
\text { based adhesive }\end{array}$ \\
\hline 8 & $\begin{array}{l}\text { Polypropylene bioriented } \\
\text { coextruded/Polypropylene } \\
\text { bioriented coextruded } \\
\text { metallized }\end{array}$ & $\begin{array}{l}\text { BOPPcoex./ } \\
\text { BOPPcoex.met }\end{array}$ & $20 / 20$ & $\begin{array}{l}2.0-2.5 \mathrm{~g} \mathrm{~m}^{-2} \\
\text { solventless adhesive }\end{array}$ \\
\hline 9 & $\begin{array}{l}\text { Polypropylene bioriented } \\
\text { coextruded/Polypropylene } \\
\text { bioriented coextruded }\end{array}$ & $\begin{array}{l}\text { BOPPcoex./ } \\
\text { BOPPcoex }\end{array}$ & $20 / 20$ & $\begin{array}{l}2.0-2.5 \mathrm{~g} \mathrm{~m}^{-2} \\
\text { solventless adhesive }\end{array}$ \\
\hline
\end{tabular}


Permeance calculation for the samples, using the manometric operating method B (only the bottom sample surface is evacuated), was determined from Equation (1).

$$
q=k_{1} \frac{V}{N \cdot T}
$$

where

$$
\begin{aligned}
& k_{1}=3.42 \times 10^{7} \\
& q=\text { permeance unit }\left(\mathrm{cm}^{3} \mathrm{~m}^{-2} \mathrm{~d}^{-1} \mathrm{bar}^{-1}\right) \\
& V=\text { measurement volume }(\mathrm{mL}) \\
& N=\text { slope of the measurement curve (s) } \\
& T=\text { temperature }(\mathrm{K}) .
\end{aligned}
$$

The permeability coefficient of the gas in film was calculated according to the following equations:

\section{Permeability Coefficient}

$$
P=k_{2} q l
$$

where:

$$
\begin{aligned}
& k_{2}=1.16 \times 10^{-9} \\
& l=\text { polymer thickness }(\mathrm{cm})
\end{aligned}
$$

Activation Energy for Permeability Coefficient

$$
P=P_{\mathrm{o}} \exp \left(\frac{-E_{p}}{R T}\right)
$$

where:

$$
\begin{aligned}
& P_{\mathrm{o}}=\text { the pre-exponential factor } \\
& R=\text { the gas constant }\left(\mathrm{J} \mathrm{mol} \mathbf{l}^{-1} \mathrm{~K}^{-1}\right) \\
& T=\text { the temperature }(\mathrm{K})
\end{aligned}
$$

Permeance characteristics changes were checked after the samples were submitted to $30,50,70$, and 110 full flex cycles at $23^{\circ} \mathrm{C}$ on a Crease Resistance Tester, Type KFT, Brugger Feinmechanik GmbH. The flexing action consists of a twisting motion followed by a horizontal motion, thus, repeatedly twisting and crushing the film [15]. The frequency is at a rate of $45 \mathrm{cpm}$ (cycle per minute).

Permeance experiments were performed three times and the mean values are reported with the standard deviation, average value, and coefficients of variability $(\%)$ for permeability coefficient $(P)$ value for the analyzed polymers in Table 2. 
Table 2. Permeability coefficient of films and laminates.

\begin{tabular}{lccc}
\hline Polymers & $\begin{array}{c}\text { Standard } \\
\text { deviation }\end{array}$ & Average & $\begin{array}{c}\text { Coefficient of } \\
\text { variability (\%) }\end{array}$ \\
\hline PE & $2.3 \times 10^{-11}$ & $2.2 \times 10^{-9}$ & 1 \\
PA & $2.8 \times 10^{-10}$ & 2 \\
BOPPcoex & $6.1 \times 10^{-12}$ & & 1 \\
BOPPcoex.met. & $4.83 \times 10^{-12}$ & $6.98 \times 10^{-10}$ & 1 \\
PA/PE & $6.14 \times 10^{-12}$ & $3.7 \times 10^{-10}$ & 2 \\
BOPPcoex/PE & $3.4 \times 10^{-11}$ & $2.1 \times 10^{-9}$ & 2 \\
BOPPcoex.met/PE & $2.8 \times 10^{-11}$ & $2.8 \times 10^{-9}$ & 1 \\
BOPPcoex./BOPPcoex.met & $1.8 \times 10^{-11}$ & $2.64 \times 10^{-9}$ & 1 \\
BOPPcoex/BOPPcoex. & $7.1 \times 10^{-12}$ & $1.12 \times 10^{-9}$ & 1 \\
\hline
\end{tabular}

\section{DSC Experiments}

The DSC analysis was carried out on a Netzsch DSC 200 differential scanning calorimeter operating in the temperature range between -100 and $500^{\circ} \mathrm{C}$ at a heating rate of $10^{\circ} \mathrm{C} \mathrm{min}-1$ in a nitrogen atmosphere. Calibrations for both the temperature and the enthalpy were achieved from measurements of melting temperature and enthalpy of indium. From DSC thermograms, the heat of fusion $\Delta H_{\mathrm{f}}$ and the degree of crystallinity $X_{\mathrm{c}}$ were determined according to the equation:

$$
X_{\mathrm{c}}=\frac{\Delta H_{\mathrm{f}}}{\Delta H_{\mathrm{f}, \mathrm{th}}},
$$

The theoretical heat of fusion $\Delta H_{\mathrm{f}, \mathrm{th}}$ of $100 \%$ crystalline polymer was assumed to be $293 \mathrm{Jg}^{-1}$ for PE and $190 \mathrm{Jg}^{-1}$ for PP and PA [16].

\section{RESULTS AND DISCUSSION}

\section{Thermal Properties}

Figure 1 shows the results of DSC measurements on as-received films. The curves exhibit one or two endothermic peaks that correspond to the 


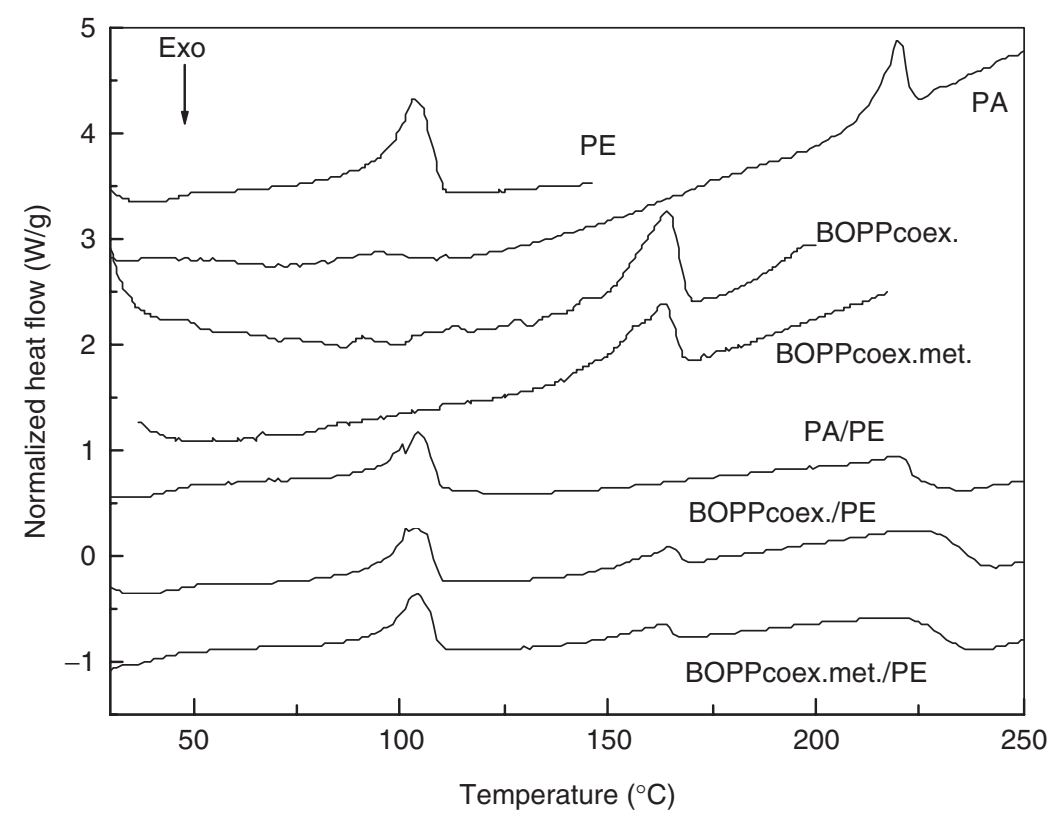

Figure 1. DSC thermograms of as-received films obtained at heating rate of $10^{\circ} \mathrm{C} \mathrm{min}-1$.

melting of crystalline phases of semi-crystalline polymers. All parameters obtained from DSC measurements on the investigated specimens are summarized in Table 3 , where $T_{\text {onset }}$ and $T_{\text {end }}$ refer to the temperature of the onset and end of the melting process and $T_{\mathrm{m}}$ is the melting temperature (DSC peak temperature).

For PA/PE laminate, it was difficult to estimate PA heat of fusion due to the overlapping of PA melting with the onset of PE oxidation. On the assumption that polymers in laminates have the same degree of crystallinity, the approximate content of polymers and tie-layers (or adhesive coatings) can be calculated. In $\mathrm{PA} / \mathrm{PE}$ and $\mathrm{BOPP} / \mathrm{PE}$ laminates, a minor peak appears in the DSC thermograms at about $101^{\circ} \mathrm{C}$ while the main peak is around $104^{\circ} \mathrm{C}$. These findings indicate that the crystalline structure did change during the production of multilayer films, probably because of the tempering at a temperature of about $100^{\circ} \mathrm{C}$. During tempering, crystal segregation occurs. Amorphous domains of highest order in the molecular structure can form crystallites with melting points higher than the temperature where the tempering was done. Complete melting deletes any thermal history as shown previously [17].

Figure 2 and Table 3 show that the crystallization behavior of $\mathrm{PE}$ was not seriously affected by mechanical stress. 
Table 3. Parameters of investigated films obtained from DSC measurements.

\begin{tabular}{|c|c|c|c|c|c|}
\hline Sample & $T_{\text {onset }}\left({ }^{\circ} \mathrm{C}\right)$ & $T_{\text {end }}\left({ }^{\circ} \mathrm{C}\right)$ & $T_{m}\left({ }^{\circ}\right)$ & $\triangle H_{\mathrm{f}}\left(\mathrm{J} \mathrm{g}^{-1}\right)$ & $X_{c}(\%)$ \\
\hline $\mathrm{PE}$ & 42 & 110 & 103 & 92 & 31 \\
\hline PE stressed (110 cycles) & 40 & 112 & 108 & 105 & 36 \\
\hline PA & 202 & 223 & 220 & 30 & 16 \\
\hline BOPPcoex & 128 & 168 & 165 & 72 & 38 \\
\hline BOPP coex.met. & 130 & 168 & 163 & 50 & \\
\hline \multirow[t]{2}{*}{$\mathrm{PA} / \mathrm{PE}$} & 40 (PE) & 110 (PE) & 104 (PE) & - & \\
\hline & - & 226 (PA) & 219 (PA) & 75 (PA) & \\
\hline \multirow[t]{2}{*}{ BOPP coex./PE } & 41 (PE) & $110(\mathrm{PE})$ & $104(\mathrm{PE})$ & 54 (PE) & \\
\hline & 145 (BOPP) & 169 (BOPP) & 165 (BOPP) & 12 (BOPP) & \\
\hline \multirow[t]{2}{*}{ BOPP coex.met./PE } & 41 (PE) & $110(\mathrm{PE})$ & $104(\mathrm{PE})$ & 45 (PE) & \\
\hline & 145 (BOPP) & 167 (BOPP) & 163 (BOPP) & 10 (BOPP) & \\
\hline
\end{tabular}

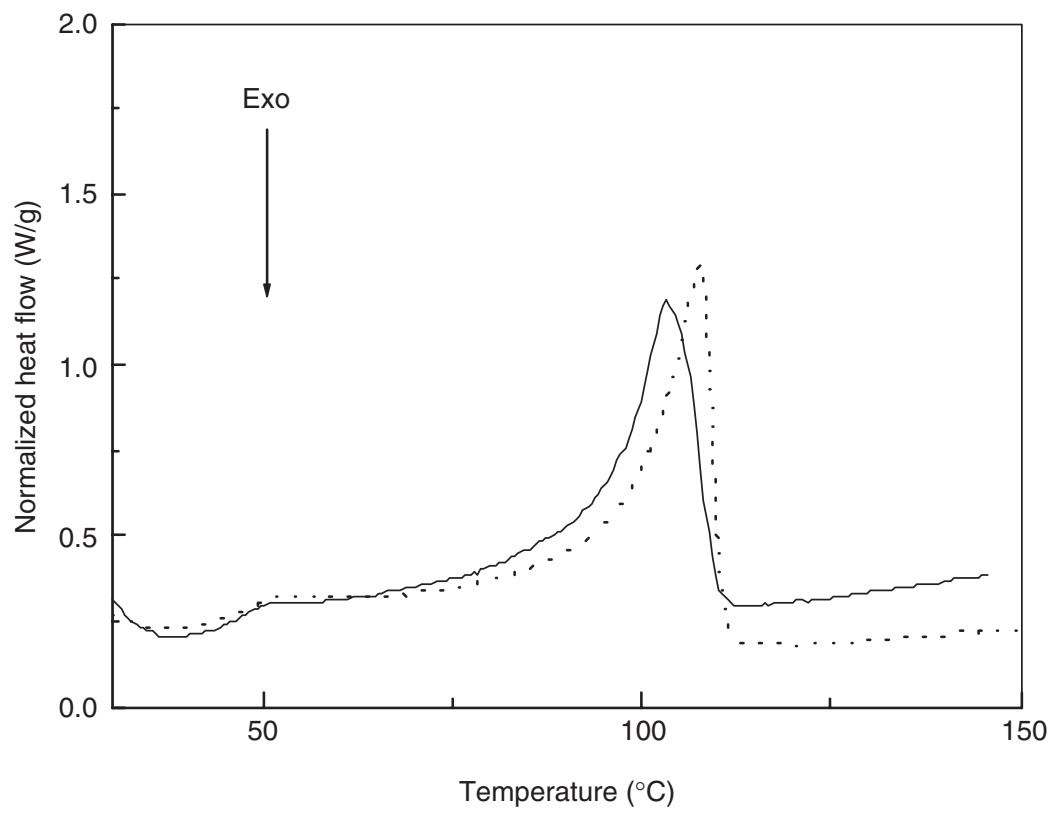

Figure 2. DSC thermograms of as-received (solid line) and stressed (110 crease stress cycles, dotted line) $\mathrm{PE}$ films obtained at heating rate of $10^{\circ} \mathrm{C} \mathrm{min}^{-1}$.

\section{Permeance Properties}

The effect of mechanical stress is presented for 50 and 110 stress cycles as very similar data were obtained for gas permeance in the lower (from 30 to 50) and higher (from 70 to 110) stress cycle range applied. 
In the case of $\mathrm{PE}$ (Figure 3), the highest permeance values (2100-7500 $\left.\mathrm{cm}^{3} \mathrm{~m}^{-2} \mathrm{~d}^{-1} \mathrm{bar}^{-1}\right)$, for all gases investigated, are obtained at higher temperatures $\left(50-60^{\circ} \mathrm{C}\right)$. It is generally assumed that the free volume in a polymer is increased by raising the temperature [18].

As shown in Figure 2 and Table 3, the crystallization behavior of PE was not seriously affected by the flex test - the minor changes could be due to the inhomogeniety of the sample. As identical trends and similar values were obtained for all gases, with some exceptions which will be commented on later, the $\mathrm{O}_{2}$ permeability data were used as representative for both monofilms (Figure 3) and laminates (Figure 4).

Although there is no great difference between the sizes of $\mathrm{N}_{2}, \mathrm{O}_{2}$, and $\mathrm{CO}_{2}$ molecules, according to literature data the permeability of polymers to $\mathrm{CO}_{2}$ is at least 4 times that of $\mathrm{O}_{2}[18,19]$; however, this was not the case for the samples in this series as will be discussed later.

PA film showed the highest increase of $\mathrm{O}_{2}$ permeability with increased stress cycles (Figure 3), while a negligible effect of stress cycles from 30 to 70 was observed in the case of $\mathrm{N}_{2}$ and air permeability. High permeability changes due to mechanical stress were also observed for BOPPcoex.met where $\mathrm{O}_{2}$ permeability (Figure 3) increased with stress cycle increase $(\geq 50$ cycles) in the entire temperature range investigated. In the case of $\mathrm{CO}_{2}$, significant permeability increase was obtained (above $40^{\circ} \mathrm{C}$ ) for 110 cycles applied, and for $\mathrm{N}_{2}$ when 70 and 110 cycles were applied, at temperature $>20^{\circ} \mathrm{C}$.

The results of G'Sell et al. [20] showed that structural damage takes place as the plastic deformation proceeds in tension, while only little damage is recorded in shear.

Another important feature, according to the same authors [20], is the progressive damage suffered by the semicrystalline structure at large strains. The evidence of this phenomenon, for both $\mathrm{PE}$ and $\mathrm{PP}$, is the decrease of density probably due to progressive fragmentation of crystallites and micro-cavitations at stress concentrated zones.

The effect of mechanical stress on gas permeance of BOPPcoex/PE laminate was observed at 50 cycles applied and did not change with further cycles (Figure 4). For BOPPcoex.met/PE a slight increase in permeance was observed even at 30 cycles for all gases investigated, while with further stress cycles a negligible effect on permeance was observed.

Generally the highest changes in gas permeance with increased stress cycles were observed with films having a metallized layer in the structure, namely BOPPcoex/BOPPcoex.met and, to a lesser extent, BOPPcoex.met/PE laminates. Similar observation was reported by Oliveira et al. [3]. Although the barrier properties of metallized 


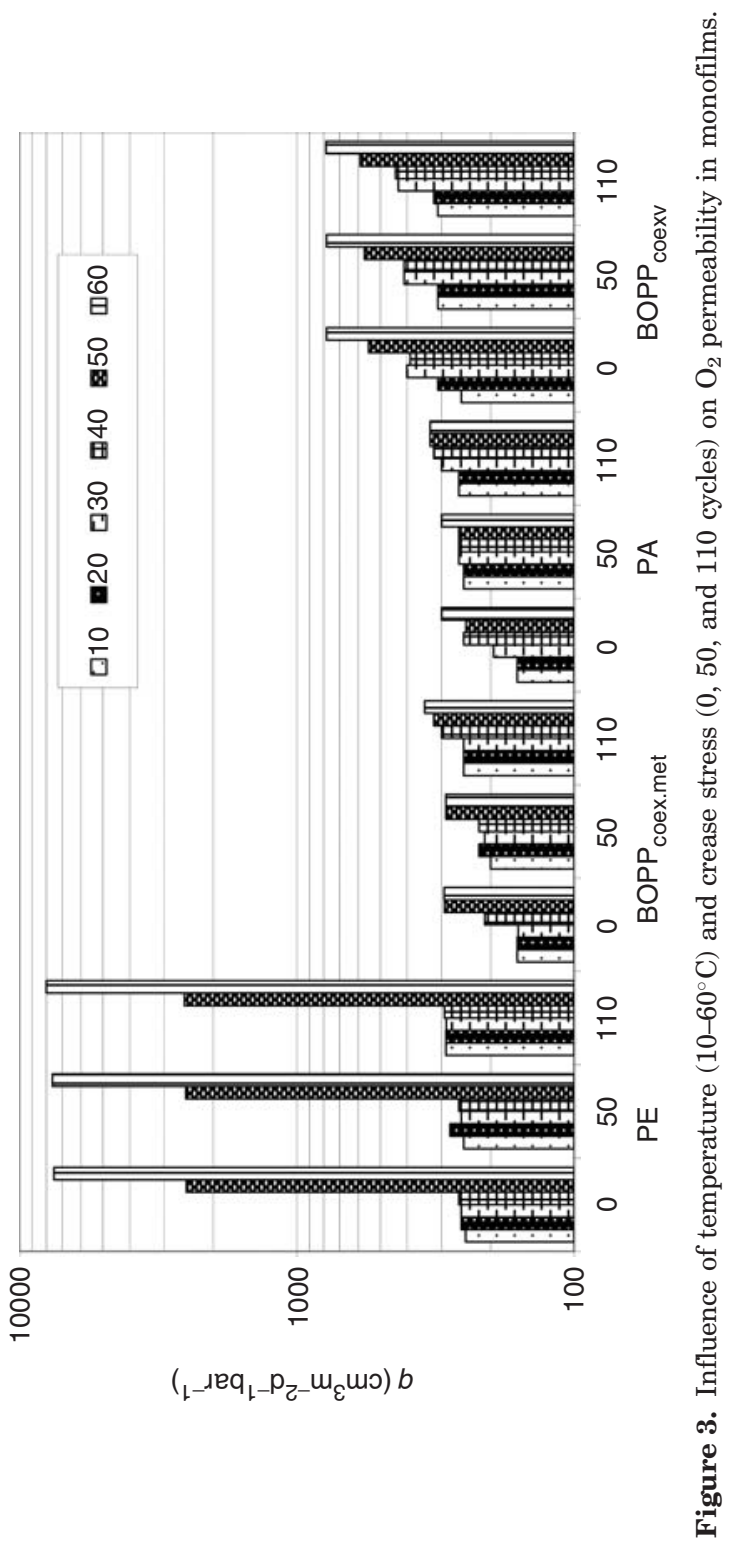




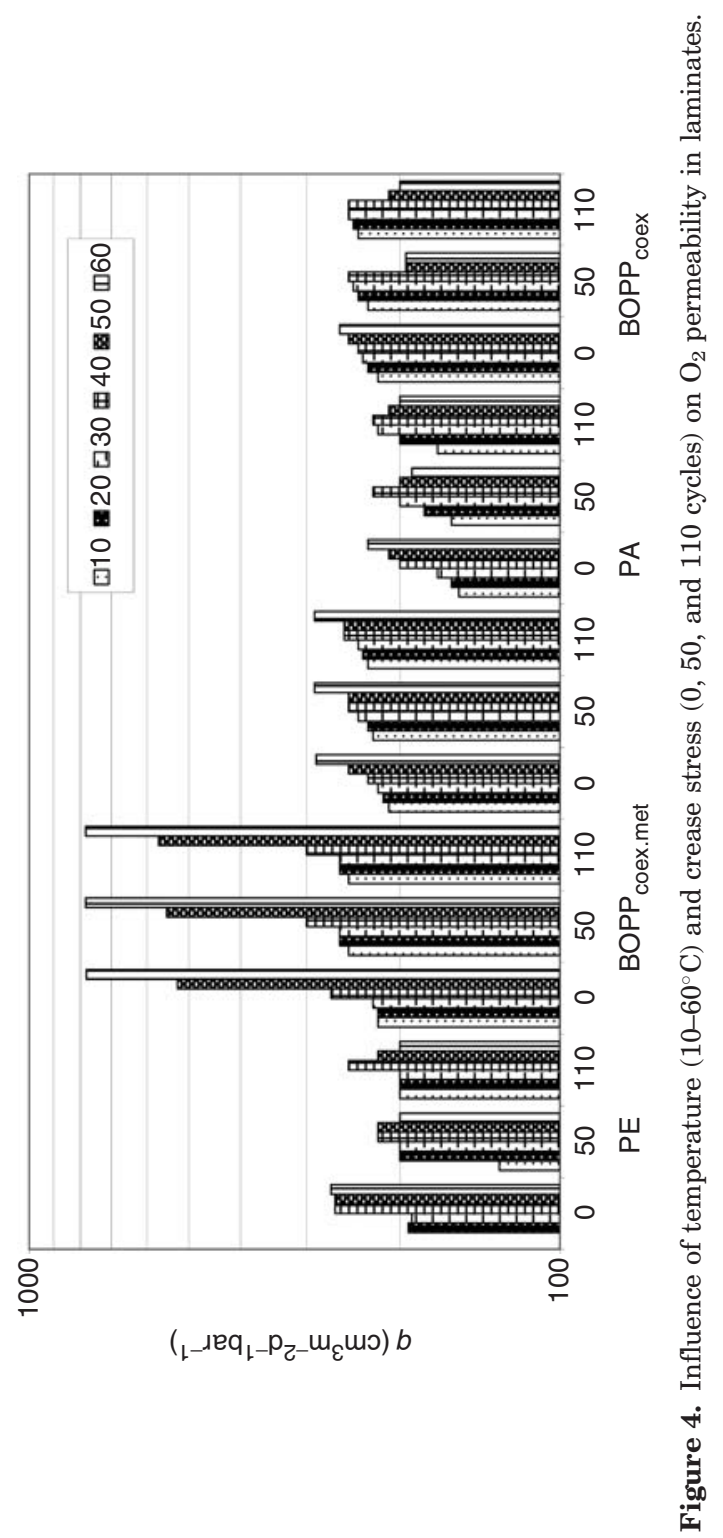


polymers are improved they are susceptible to roughening of the surface during growth, and to the incorporation of voids and pinholes during the deposition of the film [21]. For $\mathrm{SiO}_{x}, \mathrm{Al}$, and $\mathrm{AlO}_{x}$ coated films the $\mathrm{O}_{2}$ permeance rate was shown to be related to surface roughness of the barrier film, indicating that pinhole defects are not the only source of permeation through barrier films [22].

The analyzed samples were checked for cracks and/or pinhole presence. No such evidence was found by backlighting the samples and/or by applying alcoholic solution of rhodamine on the samples placed on a sheet of filter paper. The BOPPcoex/BOPPcoex.met laminate even showed decreases in gas permeance with increased stress cycles when measured at higher temperatures $\left(>40^{\circ} \mathrm{C}\right)$. A similar observation was obtained for $\mathrm{O}_{2}$ permeance only in BOPPcoex/ BOPPcoex laminate (Figure 4), while there was negligible influence of stress cycles on $\mathrm{N}_{2}, \mathrm{CO}_{2}$, and air permeance.

As for the PA/PE laminate, the effect of mechanical stress was more pronounced at 70 and 110 cycles applied, in the case of $\mathrm{CO}_{2}$ (Figure 5) and air permeance when measured above $40^{\circ} \mathrm{C}$. On the contrary, $\mathrm{O}_{2}$ (Figure 4) and $\mathrm{N}_{2}$ permeance are the highest, at $t \geq 40^{\circ} \mathrm{C}$, for the unstressed PA/PE.

Among the investigated monofilms the highest $\mathrm{O}_{2} / \mathrm{CO}_{2}$ permselectivity (Figure 6) was obtained for BOPPcoex at $10-30^{\circ} \mathrm{C}$. In this case the $\mathrm{O}_{2} / \mathrm{CO}_{2}$ selectivity decreases with increased stress cycles at $t \geq 40^{\circ} \mathrm{C}$. As previously reported [17] BOPPcoex showed the highest $\mathrm{O}_{2}$ solubility and the lowest $\mathrm{O}_{2}$ diffusivity.

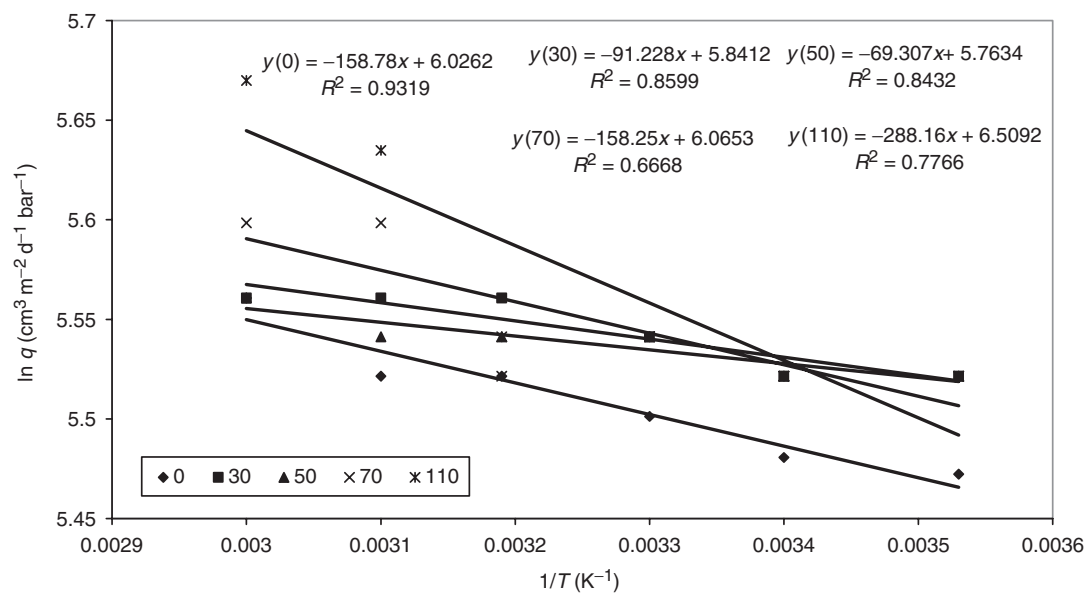

Figure 5. Influence of temperature $(1 / T)$ and crease stress cycles $(0-110)$ on $\mathrm{CO}_{2}$ transmission rate through $\mathrm{PA} / \mathrm{PE}$ laminate. 


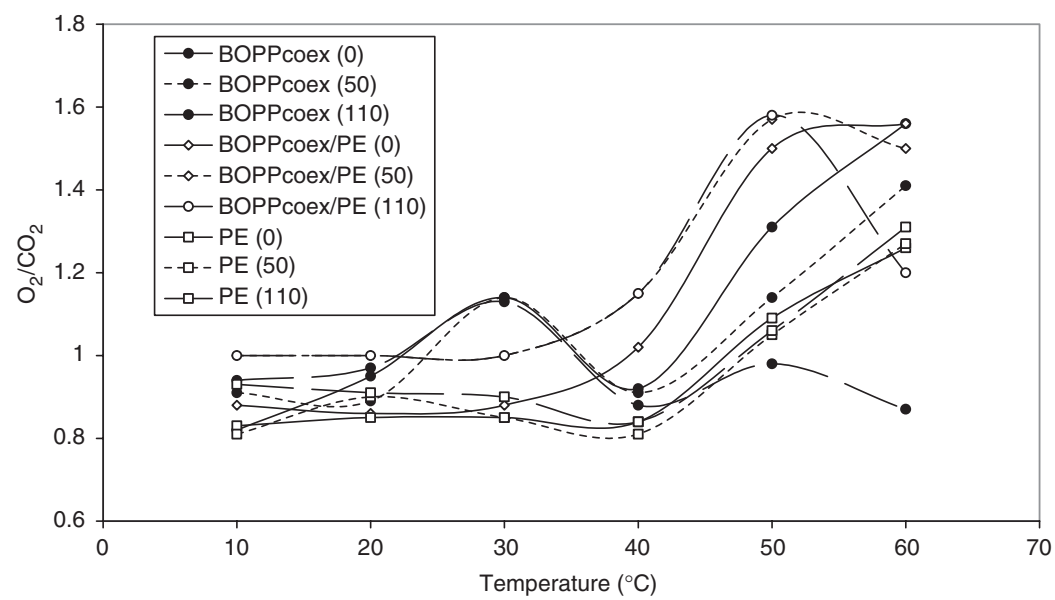

Figure 6. Effect of temperature $\left(10-60^{\circ} \mathrm{C}\right)$ and stress cycles $(0,50,110)$ on $\mathrm{O}_{2} / \mathrm{CO}_{2}$ permselectivity of some polymers.

As for the laminates, the highest $\mathrm{O}_{2} / \mathrm{CO}_{2}$ selectivity was shown by BOPPcoex/PE, with remarkable increase at $t>40^{\circ} \mathrm{C}$. For this laminate, the diffusivity and solubility for both $\mathrm{O}_{2}$ and $\mathrm{CO}_{2}$ increased at $t>40^{\circ} \mathrm{C}$ [17]. With increased mechanical stress on BOPPcoex/PE the $\mathrm{O}_{2} / \mathrm{CO}_{2}$ selectivity also increased at $10-50^{\circ} \mathrm{C}$.

The permselectivity, as reported by Zimmerman and Koros [23], increases because the matrix has a great ability to selectively distinguish between molecules of similar size: kinetic diameters for $\mathrm{O}_{2}$ and $\mathrm{CO}_{2}$ are $3.46 \times 10^{-8} \mathrm{~cm}$ and $3.30 \times 10^{-8} \mathrm{~cm}$, respectively [24]. Only PE film showed no influence of mechanical stress on $\mathrm{O}_{2} / \mathrm{CO}_{2}$ selectivity changes (Figure 6).

An increased $\mathrm{O}_{2} / \mathrm{CO}_{2}$ permselectivity is obtained for the following films exposed to stress cycles:

$\mathrm{PA}\left(10-60^{\circ} \mathrm{C}\right)$

BOPPcoex.met $\left(10-40^{\circ} \mathrm{C}\right)$;

BOPPcoex/PE $\left(10-50^{\circ} \mathrm{C}\right)$;

BOPPcoex.met/PE $\left(10-40^{\circ} \mathrm{C}\right)$;

BOPPcoex/BOPPcoex.met $\left(10-40^{\circ} \mathrm{C}\right)$

A decreased $\mathrm{O}_{2} / \mathrm{CO}_{2}$ permselectivity is obtained for the following films exposed to stress cycles:

BOPPcoex $\left(40-60^{\circ} \mathrm{C}\right)$;

$\mathrm{PA} / \mathrm{PE}\left(t>30^{\circ} \mathrm{C}\right)$;

BOPPcoex/BOPPcoex $\left(t \geq 40^{\circ} \mathrm{C}\right)$ 


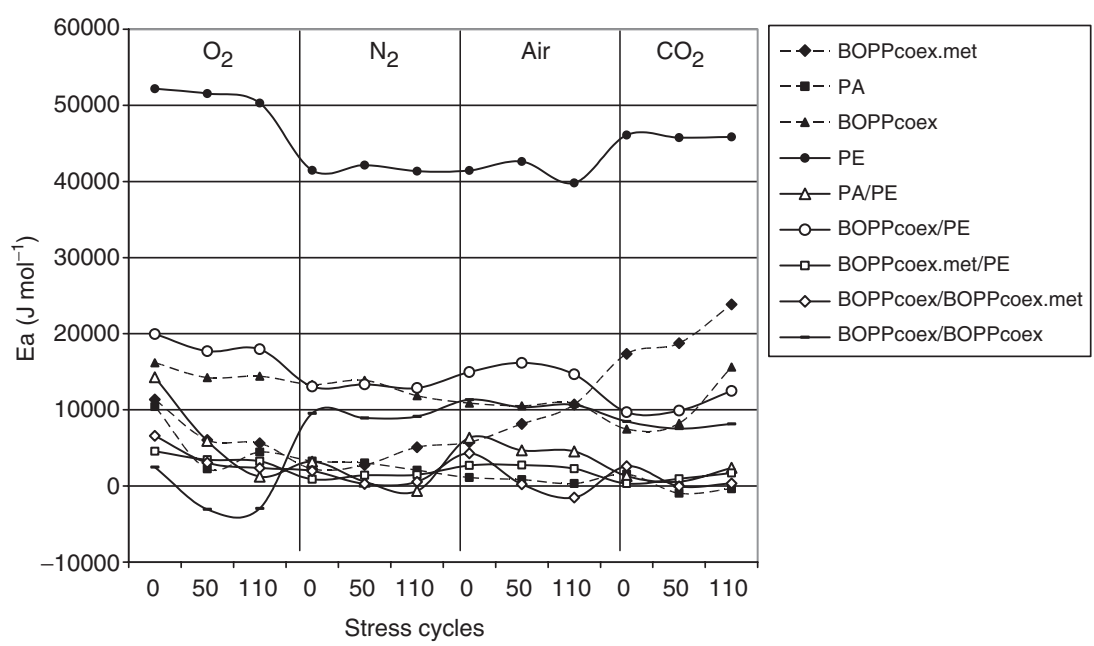

Figure 7. The effect of crease stress $(0,50$, and 110 cycles) on activation energy for the gas permeability coefficient through polymers.

This loss in selectivity is generally interpreted as plasticization: a weakening effect on the polymer introduced by the strongly sorbing $\mathrm{CO}_{2}[25]$.

Permeability increase with temperature is mostly due to enhanced motion of the polymer segments and increased energy level of permeating molecules [18]. Furthermore, high temperature causes larger gaps in the polymer matrix. Activation energy for the gas permeability coefficient $(P)$ was the highest for PE film (Figure 7). Normal progressions of activation energies for $P$ are: $\mathrm{N}_{2}=$ Air $>\mathrm{CO}_{2}>\mathrm{O}_{2}$.

According to Mano et al. [26] the curvature observed in the Arrhenius plots for PE, which also agrees well with the data [17], can be explained by two approaches. In the first case, two separate processes were assumed to contribute to the $\alpha$-relaxation, with activation energies of 150-170 and $180-210 \mathrm{~kJ} \mathrm{~mol}^{-1}$, respectively (dynamic data). The activation energies obtained from creep are lower than those obtained from dynamic mechanical experiments, reflecting a dependence of activation energy, a microscopic property, on the selected experimental technique [26]. Matsuo et al. [27] also concluded that a decrease in the activation energies was observed in PE films with increasing drawing levels, i.e., with increasing orientation within the crystalline phase.

Korsukov et al. [28], for example, have reported that aldehyde groups are produced in PE and PP at an increased rate when stress is applied. The reason applied stress leads to a more rapid rate of reaction is that 
mechanical tension contributes to chemical bond scission. The thermal energy of activation is lowered by the potential energy of the stress. If the mechanism of the reaction at higher or lower temperatures should differ, this too would alter the slope of the curve. Numerous examples of non-linear Arrhenius plots, the consequence of a change in mechanism, can be found in the literature [29-32].

Laminates with metallized layer (BOPPcoex.met/PE and BOPPcoex/ BOPPcoex.met) show much lower activation energy, due to metallic layer damage by flexing, in comparison to laminates without a metallized layer (BOPPcoex/PE and BOPPcoex/BOPPcoex). As regards activation energy value (Figure 7), the presence of $\mathrm{PE}$ layer in laminates (PA/PE; BOPPcoex/PE) enables material to preserve better barrier properties to $\mathrm{O}_{2}$ and air than to $\mathrm{CO}_{2}$ and $\mathrm{N}_{2}$.

The lowest activation energy is obtained for $\mathrm{O}_{2}$ permeation through BOPPcoex/BOPPcoex laminate, while much higher values are obtained for $\mathrm{N}_{2}$, air, and $\mathrm{CO}_{2}$ permeability. Excellent correlation (from $r=0.584$ to $r=0.995$ ) between activation energy and molecular diameter of permeates is obtained for the samples exposed to 50 stress cycles. Poor correlation exists in the case of three materials (PE, BOPPcoex, and $\mathrm{PA} / \mathrm{PE}$ ) exposed to 110 stress cycles.

\section{CONCLUSIONS}

Generally, the highest variation in gas permeance changes with increased stress cycles, observed with films having a metallized layer in the structure, namely BOPPcoex/BOPPcoex.met and, to a lesser extent, BOPPcoex.met/PE laminate.

The lowest effect of mechanical stress on gas permeance was noticed for PE; BOPPcoex/PE, and BOPPcoex/BOPPcoex films. Similar behavior was noticed for BOPPcoex with the exception of $\mathrm{CO}_{2}$ permeance which significantly increased at $60^{\circ} \mathrm{C}$ and 110 stress cycles applied.

An increased $\mathrm{O}_{2} / \mathrm{CO}_{2}$ permselectivity for metallized films (BOPPcoex.met; BOPPcoex.met/PE; BOPPcoex/BOPPcoex.met) was obtained at the lower temperature range $\left(10-40^{\circ} \mathrm{C}\right)$ in comparison with non-metallized films (BOPPcoex/PE and PA). Generally, a decrease in $\mathrm{O}_{2} / \mathrm{CO}_{2}$ permselectivity at temperature $>30^{\circ} \mathrm{C}$ was obtained with increased flexing for BOPPcoex, $\mathrm{PA} / \mathrm{PE}$, and BOPPcoex/BOPPcoex.

Thus, it is highly recommended to apply mechanical stresses at 50 full flex cycles before measuring the permeability at different temperatures to determine their influence on barrier characteristics of flexible materials used for food packaging. 


\section{ACKNOWLEDGMENTS}

The research was supported by the Ministry of Science and Technology, Croatia (Projects: TP-01/0058-09 and 058004) and Croatian Academy of Science and Arts.

\section{REFERENCES}

1. Klopffer, M.H. and Flaconnèche, B. (2001). Transport Properties of Gases in Polymers: Bibliographic Review, Oil \& Gas Science and Technology, 56(3): 223.

2. Galić, K., Ciković, N. and Ugarković, I. (2002). Barrier Properties of a New Generation of Packaging Materials, In: Tripalo, B. (ed.), Proceedings of the 4th Croatian Congress of Food Technologists, Biotechnologists and Nutritionists, Faculty of Food Technology and Biotechnology, Zagreb, pp. 82-87.

3. Oliveira, L.M., Sarantopoulos, C.I. and Venega, M.A. (1997). Mechanical Stress Resistance of Barrier Packaging Films, J. Plas. Film \& Shtg., 13(1): 35 .

4. Ciković, N., Galić, K., Matošević, M. and Mlinac-Mišak, M. (1998). Influence of Damage Caused by Creasing Strain on Gas Permeabilities for Modified Polyethylene Foils, Polimeri, 19(2): 19-24.

5. Arvanitoyannis, I., Psomiadou, E. and Biliaderis, C.G. (1997). Biodegradable Films Made from Low Density Polyethylene (LDPE), Ethylene Acrylic Acid (EAA), PolyCaprolactone (PCL) and Wheat Starch for Food Packaging Applications: Part 3, Starch/Stärke, 49(7-8): 306-322.

6. Wang, L.H. and Porter, R.S. (1984). On the $\mathrm{CO}_{2}$ Permeation of Uniaxially Drawn Polymers, J. Polym. Sci. Polym. Phys. Ed., 22(9): 1645-1653.

7. Yang, W., Li, Z.-M., Xie, B.-H., Feng, J.-M., Shi, W. and Yang, M.-B. (2003). Stress-induced Crystallization of Biaxially Oriented Polypropylene, J. Appl. Polym. Sci., 89(3): 686-690.

8. Jarus, D., Hiltner, A. and Baer, E. (2002). Barrier Properties of Polypropylene/Polyamide Blends Produced by Microlayer Coextrusion, Polymer, 43(8): 2401-2408.

9. Yasuda, H. and Peterlin, A. (1974). Gas Permeability of Deformed Polyethylene Films, J. Appl. Polym. Sci., 18(2): 531-546.

10. Chu, F. and Kimura, Y. (1996). Structure and Gas Permeability of Microporous Films Prepared by Biaxial Drawing of $\beta$-form Polypropylene, Polymer, 37(4): 573-579.

11. Hu, Y.S., Prattipati, V., Mehta, S., Schiraldi, D.A., Hiltner, A. and Baer, E. (2005). Improving Gas Barrier of PET by Blending with Aromatic Polyamides, Polymer, 46(8): 2685-2698. 
12. ISO 2556:1974 Plastics - Determination of the Gas Transmission Rate of Films and Thin Sheets under Atmospheric Pressure - Manometric Method.

13. ASTM D1434-82 - Standard Test Method for Determining Gas Permeability Characteristics of Plastic Film and Sheeting - Two Test Methods are Provided - Procedure M (Manometric) and Procedure V (Volumetric).

14. Brugger Feinmechanik GmbH (1993). Gas Permeability Testing Manual, Registergericht Müchen HRB 77020.

15. ASTM F392-74 (Reapproved 1979). Standard Test Method for Flex Durability of Flexible Barrier Materials.

16. Brandrup, J. (1989). Polymer Handbook, Vol. 109, Wiley, New York.

17. Mrkić, S., Galić, K., Ivanković, M., Hamin, S. and Ciković, N. (2006). Gas Transport and Thermal Characterization of Mono- and Di-polyethylene Films Used for Food Packaging, J. Appl. Polym. Sci., 99(4): 1590-1599.

18. Naylor, T. V. (1989) Permeation Properties, In: G. Allen, J.C. Bevington, C. Booth and C. Price (eds.) Comprehensive Polymer Science, Vol. 1, Pergamon Press, Oxford, pp. 643-668.

19. Mathlouthi, M. (1989). Food Packaging and Preservation, Elsevier Applied Science Publishers, New York, pp. 9-10, 25-38.

20. G'Sell, C., Favier, V., Dahoun, A., Hiver, J.M., Philippe, M.J. and Canova, G.R. (1997). Microstructure Transformation and Stress-Strain Behaviour of Isotactic Polypropylene Under Large Plastic Deformation, Polym. Eng. Sci., 37(10): 1702-1711.

21. Moosheimer, U. and Langowski, H.-C. (1999). Permeation of Oxygen and Moisture through Vacuum Web Coated Films, Society of Vacuum Coaters Proceedings 42nd Annual Technical Conference, Chicago, pp. 408-414.

22. Henry, B.M., F. Dinelli, W.J., Zhao, K.-Y., Grovenor, C.R.M., Kolosov, O.V., Briggs, G.A.D., Roberts, A.P., Kumar, R.S. and Howson, R.P. (1999). A Microstructural Study of Transparent Metal Oxide Gas Barrier Film, Thin Solid Films, 355-356(1Nov99): 500-505.

23. Zimmerman, C.M. and Koros, W.J. (1999). Polypyrrolones for Membrane Gas Separation. I. Structural Comparison of Gas Transport and Sorption Properties, J. Polym. Sci. Polym. Phys. Ed., 37(12): 1235-1249.

24. Shieh, J.-J. and Chung, T.S. (1999). Gas Permeability, Diffusivity, and Solubility of Poly (4-Vinylpyridine) Film, J. Polym. Sci. Polym. Phys. Ed., 37(20): 2851-2861.

25. Kamiya, Y., Hirose, T., Mizoguchi, K. and Naito, Y. (1986). Gravimetric Study of High-Pressure Sorption of Gases in Polymers, J. Polym. Sci. Polym. Phys. Ed., 24(7):1525-1539.

26. Mano, J.F., Sousa, R.A., Reis, R.L., Cunha, A.M. and Bevis, M.J. (2001). Viscoelastic Behaviour and Time-temperature Correspondence of 
HDPE with Varying Levels of Process-induced Orientation, Polymer, 42(14): 6187-6198.

27. Matsuo, M., Sawatari, C. and Ohhata, T. (1988). Dynamic Mechanical Studies on Crystal Dispersion Using Ultradrawn Polyethylene Films, Macromolecules, 21(5): 1317-1324.

28. Korsukov, V.E., Vettegren, V.I. and Novak, J.J. (1973). Kinetics of Destruction of Stressed Polymers, J. Polym. Sci. Symposium, 42(3): 1299-1304.

29. Hawkins, W.L., Matreyek, W. and Winslow, F.H. (1959). The Morphology of Semicrystalline Polymers. Part I. The Effect of Temperature on the Oxidation of Polyolefin, J. Polym. Sci. Polym. Phys. Ed., 41(1): 1-10.

30. Hartley, G.H. and Guillet, J.E. (1968). Photochemistry of Ketone Polymers. I. Macromolecules, 1(2): 165-170.

31. Chodak, I. and Zimanyova, E. (1984). The Effect of Temperature on Peroxide Initiated crosslinking of polypropylene, European Polym. J., 20(1): 81-84.

32. Kramer, E. and Koppelmann, J. (1987). Thermo-oxidative Degradation of Polyolefins Observed by Isothermal Long-term DTA, Polym. Eng. Sci., 27(13): 945-954.

\section{BIOGRAPHIES}

\section{Saša Mrkić}

Saša Mrkić obtained his BS Food Technology at the University of Zagreb. After working in the bakery industry for a few years he attended the University of Zagreb, Faculty of Food Technology and Biotechnology where he did research work in food packaging materials while he obtained his $\mathrm{PhD}$ in food technology. Mrkic is now employed in the confectionary industry.

\section{Kata Galić}

Kata Galić received her BS Biotechnology from the University of Zagreb and then obtained her MSc and $\mathrm{PhD}$ degrees from the University of Zagreb, Faculty of Food Technology and Biotechnology. Her research interests have included permeability characteristics of polymeric materials and factors affecting barrier changes of polymers. She has received several fellowships during her career and presented 32 scientific and 20 professional papers. Galic has been on the faculty of the University of Zagreb for 24 years. She is now a professor at the University of Zagreb, Faculty of Food Technology and Biotechnology 
where she was vice-dean for international scientific cooperation. Galic is a member of the Institute for Packaging in Croatia.

\section{Marica Ivanković}

Marica Ivanković obtained her BS in Chemical Technology and her MS in engineering chemistry from the University of Zagreb before spending three years at the Department of Materials and Production Engineering at the University of Naples, Italy. She returned to the University of Zagreb where she obtained her $\mathrm{PhD}$ in chemical engineering from the Faculty of Chemical Engineering and Technology. She has performed research in thermodynamics of polymer solutions as well as the synthesis and characterization of organicinorganic hybrids and nanocomposites. Ivankovic has published 40 papers and has been active in several engineering organizations. She is a professor at the University of Zagreb, Faculty of Chemical Engineering and Technology, where she has been a member of the faculty for 22 years. 